\title{
25 Research Square \\ Gender Differences in Parenting of Early Adolescents in Viwandani Informal Settlement, Nairobi: a Qualitative Study
}

Vivian Nyansarora Nyakangi ( $\sim$ vnyakangi@aphrc.com )

APHRC: African Population and Health Research Center https://orcid.org/0000-0002-6220-7256

Beatrice Maina

APHRC: African Population and Health Research Center

Michelle Mbuthia

APHRC: African Population and Health Research Center

Martin Bangha

APHRC: African Population and Health Research Center

Research

Keywords: Early adolescents, gendered parenting, gender norms, gender equality, informal urban settlements, Nairobi, Kenya

Posted Date: January 28th, 2021

DOl: https://doi.org/10.21203/rs.3.rs-154056/v1

License: (9) This work is licensed under a Creative Commons Attribution 4.0 International License.

Read Full License 


\section{Abstract}

Background: Parenting in adolescence is gendered in many dimensions including communication, control, discipline and styles of parenting. Gendered parenting reinforces harmful stereotypical gender norms which can lead to gender inequalities in society. Gender inequalities put adolescent boys and girls at a heightened risk of poor SRH outcomes

Methods: The study was conducted in an informal urban settlement, Viwandani, in Kenya's capital city, Nairobi. Focus group discussions were used to collect data from 48 parents of adolescents in grades 5 and 6 in two public day primary schools. Interviews were audio-recorded, transcribed and uploaded to NVivo 12 for coding and thematic analysis.

Findings: We found differences in parenting approaches based on the parent's and/or adolescent's gender. Based on parents' gender, fathers had more differential parenting approaches for their sons and daughters while mothers were more consistent for both boys and girls. Fathers held different expectations for their adolescent girls and boys with respect to their roles and responsibilities presently and in the future. Based on the gender of the adolescent, boys had more freedom of movement than girls and girls were more likely to be engaged in SRH discussions with parents as compared to boys. There were also differences in the roles that mothers and fathers played in the family setting.

Conclusion: Gender differences in parenting do exist along with male and female roles differing considerably within households. The disconnect in gendered beliefs between men and women implies a greater need to engage men in gender-equitable programming given they have been found to hold gender inequitable attitudes.

\section{Plain English Summary}

Gender learning intensifies in early adolescence as adolescents try to conform to different expectations for a typical man or woman in their societies. Parents play a crucial role in gender learning as primary socialization agents for adolescents. Gendered parenting can perpetuate existing unequal gender norms which are harmful to adolescents' wellbeing now and in the future. The study aimed to explore gender differences in the parenting of very young adolescents in Viwandani informal settlement, Nairobi along the dimensions of roles and responsibilities, SRH communication, freedom of movement and roles of parents in the family setting. We found that there were gender differences in roles perceived to be for boys and girls, parent-adolescent SRH communication and freedom of movement for adolescent boys and girls. There were also differences in mothers' and fathers' approaches to parenting. Mothers tended to be more gender equitable in comparison to fathers especially in the perception of roles for boys and girls now and in the future. Gendered parenting can perpetuate harmful stereotypical norms in societies. Having community-level interventions that are geared towards deconstructing such norms and addressing traditional beliefs held by both men and women is important in avoiding such norms from being passed down to coming generations from their parents. 


\section{Background}

Early adolescence-the period between 10 to 14 years-is a transitory period characterized by rapid changes physically, psychologically and socially $(1,2)$ marking the onset of puberty for both boys and girls (2). Adolescents' social-cognitive abilities develop rapidly in early adolescence, enhancing their interpretation and understanding of what they observe especially from people within their contexts, such as parents (3). The pressure to conform to societal expectations on gender norms also begins to intensify during this period (4). Parents begin to change how they engage with boys and girls (5), adapting to the physical, psychological and social changes occurring within adolescents.

Parenting in adolescence is gendered in many dimensions including communication (6-8), control (9), discipline and styles of parenting (10). For instance, sexual and reproductive health (SRH) communication is commonly delivered by mothers and rarely fathers, and girls are commonly targeted in SRH messages (7). Parents also tend to employ different parenting styles to adolescent girls and boys, with those used on boys being more demanding and less responsive (authoritarian) while those of girls are both demanding and responsive (authoritative) (10-12). Gendered parenting reinforces harmful stereotypical gender norms which can lead to gender inequalities in society (13). Gender inequalities put adolescent boys and girls at a heightened risk of poor SRH outcomes (14).

The Social Cognitive Theory of gender development posits that gender socialization is a complex process involving both cognitive and social processes (15). Parents are primary socialization agents and gender models to their children $(16,17)$. They demonstrate how men and women behave and interact in society, in the roles they take up and their different interactions with their sons and daughters. Parents also pass on gender ideas and expectations through explicit and implicit messages on how adolescents are expected to behave based on their gender (18). Adolescents from families characterized by more traditional gender role attitudes are likely to adopt more gender-stereotypical beliefs $(13,19)$. Additionally, adolescents are likely to take up behaviors from a person they identify with i.e. boys are likely to adopt masculine roles and behaviors, identifying with their fathers, while girls adopt feminine roles and behaviors, similar to mothers $(15,16)$.

While research has shown that mothers are the main caregivers of adolescents (20) and play the greater role in their nurturing, little is known about the ways in which fathers and mothers differ with regard to the different parenting dimensions in urban informal settlements. We recognise that there are subtle ways in which parents may reinforce gender norms even implicitly by how they interact and communicate with adolescents. Parenting in informal urban settlements poses an additional challenge due to financial hardship and social vulnerabilities that parents and adolescents have to contend with (21). Informal urban settlements in Nairobi are characterised by high rates of unemployment, extreme poverty, overcrowding, and high rates of crime $(22,23)$. Additionally, adolescents are exposed to risky sexual behaviours, alcohol and substance abuse at an early age (24-26). This gives parents an additional responsibility of ensuring that adolescents navigate these harsh environments safely. 
The main aim of this paper, therefore, is to explore gender differences in parenting of early adolescents in Viwandani, an informal settlement in Nairobi, along the dimensions of gender role expectations of parents for their adolescents, parent-adolescent SRH communication, freedom of movement for adolescents and differences in parenting approaches between mothers and fathers.

\section{Methods}

\section{Study design and setting}

This study used qualitative data collected between May and June 2019 from 48 parents of adolescents in grades 5 and 6 in two public day primary schools in Viwandani, Nairobi. This was part of a larger school-based study focusing on the gender socialisation of very young adolescents in schools and SRH in urban informal settlements. Viwandani is one of two informal settlements covered by the Nairobi Urban Health and Demographic Surveillance System (NUHDSS); a prospective, longitudinal research study run by the African Population and Health Research Center (APHRC) since 2002 (23). As of 2019, the NUHDSS population in both sites was about 88,974 individuals living in over 33,080 households. The main source of income for the residents is casual employment in nearby industries. As with other informal settlements in the city, Viwandani is densely populated, characterized by high levels of unemployment, substandard housing, and overcrowding, limited social services, high levels of crime and insecurity, and inadequate water and sanitation infrastructure (23).

\section{Participants}

Two teachers who coordinated study activities in each of the schools participating in the study purposively sampled 48 parents ( 24 mothers and 24 fathers) of adolescents in grades 5 and 6 to participate in focus group discussions (FGDs). Parents were eligible to participate if they had an adolescent in Grade 5 or 6 in either of two study schools, were available during the time and day of the scheduled interview, expressed willingness to participate and provided informed consent to participate in FGDs and for their child(ren) to participate in the larger study.

\section{Data collection procedures}

A semi-structured FGD guide was used in the study and comprised of guiding questions on transitions to adolescence, romantic relationships, sexuality education and gender socialization. Interviews were conducted in English and Kiswahili and were moderated by a qualitative researcher assisted by two experienced qualitative research assistants.

Six FGDs, each comprising of six to ten parents/guardians (48 participants in total) were conducted. The participants were grouped by their gender and that of their adolescent child(ren) as follows: fathers of adolescent boys, fathers of adolescent girls, mothers of adolescent boys, mothers of adolescent girls, fathers of adolescent girls and boys and mothers of adolescent girls and boys. Interviews were conducted in a school within the NUHDSS and were audio-recorded (all participants gave informed consent to the audio-recording prior to participating in the study) to ensure that no elements of the 
discussions were lost. For this study, we used data collected using guiding questions that focused on transitions to adolescence, romantic relationships, sexuality education and gender socialization.

\section{Analysis of data}

Two bilingual transcribers transcribed all the audio recordings verbatim (those in English), while those in Swahili or with a mix of Swahili and English were directly transcribed to English. The research team randomly checked and proofread all the transcripts for quality assurance. Transcripts were then uploaded on NVivo 12 qualitative analysis software for inductive coding and thematic analysis. The lead author read all the transcripts and identified the emerging quotations about gendered parenting which were then labeled with a code. The codes were then reviewed, by all authors, ensuring consistency by merging codes that were similar or splitting codes that were broad. Codes were then grouped into subthemes and subthemes into themes

\section{Ethical considerations}

The protocol including tools/interview guides were reviewed and approved by AMREF Health Africa's Ethics and Scientific Review Committee (Ref AMREF-ESRC P564/2018). The National Commission for Science, Technology and Innovation in Kenya gave the permit (Ref: NACOSTI/P/19/16027/27880) to conduct the study. Additional approvals from county administration were obtained and written informed consent obtained from the parents/guardians before the commencement of the interview.

\section{Findings}

The median age of the participants was 36 years (43 for men, and 34 for women) ranging from 23-63 years. All except one were Christians. One parent had college education, about half had secondary school education and the rest had primary school education with no differences in education level between men and women. The average number of children for both men and women was three, ranging from one to nine. Data on marital and employment status were collected but were incomplete hence not presented.

Two distinct parenting approaches emerged: i) based on the gender of the child - this included differences in parental control on freedom of movement and SRH communication based on whether the child was a boy or a girl; ii) based on the gender of the parent - differences in fathers' and mothers' expectations on roles and responsibilities of their children. Fathers endorsed more traditional beliefs while mothers embraced gender equitable norms in regards to the roles and responsibilities of adolescents now and in the future.

\section{Differences in parenting approaches based on gender of the parent.}

Roles and responsibilities for boys and girls

Fathers mainly perceived that there were different roles and responsibilities traditionally meant for girls (such as house chores) and for boys (such as carrying heavy loads like a gas cylinder). According to fathers, when boys performed roles traditionally meant for girls, it was only because there were fewer 
activities traditionally meant for boys in the urban setting or they were just helping the girls. According to fathers, it was important for boys and girls to align with gender roles and expectations for males and females in society in preparation for adult life.

Culturally, we know that there is some housework for girls and for boys, for example, cooking is for girls. Even if a boy does this (cooking) they are just helping. At home, they will need to share duties and girls are responsible for the kitchen and they will only be helped when they are sick or they are held up by other work. Boys' duties are to carry refilled gas cylinders because they are heavy and because in Nairobi we don't use firewood, and also they should know where gas (cylinders) are refilled. (Fathers of adolescent boys)

Girls are supposed to know more about housework because they are the ones who will get married. So if they get married and they don't know housework, for example how to cook, it will make their husbands wonder how they were raised. So it remains that housework is for girls and boys should have their own specific work.(Fathers of adolescent boys and girls)

Mothers, on the other hand, tended to perceive the same roles and responsibilities for boys and girls.

I told him[son] that there is no specific duty for anyone so they[son and daughter] should interchange duties every day. If, for example, today he is the one who is cooking or cleaning utensils, the following day his sister will do the same. So they are supposed to do any work which I give them.(Mothers of adolescent boys and girls)

Even when boys performed household chores at a younger age, they became gender-aware in early adolescence signifying a transition from childhood to adolescence. This transition was marked by resistance to roles traditionally meant for girls with boys who performed such roles often facing social sanctions and ridicule.

I think it is natural to boys/men that there are some duties they cannot perform in an open space where they can be seen by girls/women because they fear to be laughed at. There are boys who liked to clean utensils when they were five years old but when they reach ten or twelve years old they start to hate it or they clean them while they are hiding.(Fathers of adolescent boys)

Despite the social sanctions, mothers engaged boys in household chores, albeit, forcefully.

We force them because I cannot clean utensils on weekends. If they are available I will tell them to clean utensils, fetch water, and tidy up the house. So, I usually tell them on weekends they are responsible to do everything in the house but one challenge is, they don't like washing clothes.(Mothers of adolescent boys)

Future expectations of parents for boys and girls

While both fathers and mothers expected both their sons and daughters to attain higher education, secure good jobs and get married, mothers were more explicit that they had common expectations for sons and 
daughters. On the other hand, a majority of fathers often expressed a strong expectation for their daughters to get married and become good wives with no matching expectations for their sons becoming good husbands. By being "good wives" women were expected to be submissive to their husbands, perform as housewives and primary caregivers, roles that are traditionally meant for them.

I wish all the best to my daughters to be good and reliable housewives.(Fathers of adolescent girls)

Fathers implied that girls' character determined the kind of marriage they got into. For instance, premarital childbearing for girls was associated with marital issues and thus girls were expected to delay childbearing until marriage. Such expectations did not arise for boys.

We expect girls to be good wives with a good reputation when they get married. We expect girls not to have children before they get married because it may make them not to have a good life. It is good to be married when they don't have children so that they may start life afresh and to get husbands who will protect them and to have a good life in marriage.(Fathers of adolescent boys and girls)

While a majority of fathers' future expectations for daughters mainly centered on marriage, a few fathers did expect their daughters to get an education and get a job although this was still linked to marriage. For fathers, having an education, and hence, a job would ensure a stable life for a woman in the event of marriage dissolution.

Educating a girl is beneficial even if they get they get married. When a girl is educated and has a job she can still progress with her life in case they get separated from her husband.(Fathers of adolescent boys and girls)

For mothers, being educated and having a rewarding career were as equally important as marriage for both boys and girls. With respect to girls, a mother said:

I told my child first to study up to university level and then to get a job so that when she gets married her husband will respect her since she has her own job.(Mothers of adolescent boys and girls)

Similarly for boys:

I expect him to live a good life even if they will not help me, to live well with his family and also to study well so that he may get a good job in future.(Mothers of adolescent boys)

\section{Differences in parenting approaches based on gender of the adolescent}

Differences mainly emerged in regard to how parents communicated about SRH as well as in child monitoring. These differences were associated with perceived risks which were more aggravated for girls than boys.

Parent-adolescent SRH communication 
Both mothers and fathers perceived SRH information as largely necessary for girls who are considered more vulnerable to sexual risks, unlike boys. However, fathers also perceived SRH communication to be a mother's responsibility.

It is good for mothers to have wisdom when raising girls and counsel them in advance because at anytime girls can get pregnant.(Fathers of adolescent girls)

SRH communication was mainly centered on pregnancy prevention and menstrual hygiene.

I told them[girls] that they should not play with boys or allow them[boys] to touch their[girls] bodies because the more they[boys] touch them[girls' bodies] the more the chances of getting pregnant.(Mothers of adolescent boys and girls)

There was a time one of my daughters got her first period and she became afraid of it but I told her mother to teach her about this (menses) so that she can understand that she has reached another stage of life.(Fathers of adolescent girls)

Whenever SRH communication occurred with boys, it was about avoiding to impregnate girls as they risked being arrested. There was hardly any mention of other SRH risks or safe sex practices for boys.

Boys are also at risk because they will be arrested when this happens[a girl gets pregnant]. They [police] don't investigate if it is the girl who started this[relationship] they will arrest the boy first although all of them are children.(Mothers of adolescent boys and girls)

Freedom of movement for boys and girls

Discussions about freedom of movement focused more on boys than girls. Boys had more freedom and spent most of their time outside the home without parents' knowledge of their whereabouts or their associates. This was considered normal by both fathers and mothers.

They [boys] can go somewhere the whole day and return before you come back after work.(Mothers of adolescent boys)

While it was not explicitly mentioned that girls spent more time at home or outside the home, girls, unlike boys, mostly took up household chores which were likely to keep them at home. Parents also instituted additional measures to keep girls at home. For instance, one mother said:

I decided that when schools are closed my daughter will have tuition at home because I don't like her going outside.(Mothers of adolescent girls)

With more freedom of movement, boys also got the opportunity to engage in economic activities.

At this stage (early adolescence) they[boys] know how to look for money. They can collect plastics and metals and sell but when they get money they cannot tell you. They will buy whatever they want with it. 
(Mothers of adolescent boys)

However, freedom of movement and financial empowerment did increase boys' vulnerability to harmful behaviours such as violence and substance use that are detrimental to their health and wellbeing.

When they start to do this [engage in economic activities] they start to join bad company whereby they can start to abuse drugs like bhang (Marijuana) and also become thieves.(Mothers of adolescent boys)

They (adolescent boys) are introduced to this [drugs] by their friends when they interact with them in places like PS (places where they play video games) and apart from this there are criminal groups they can join groups like Gaza and Mungiki (criminal gangs) where they are taught bad things and there are others also who are introduced to Al-Shabaab (terrorist group).(Fathers of adolescent boys and girls)

\section{Differences in roles and responsibilities of parents in adolescents' life}

The roles for fathers and mothers in parenting adolescents were different in the family setting. Fathers were more inclined to provision and protection and were often away for work whereas mothers engaged more in nurturing and guidance as they spent more time at home with the adolescents.

Their mothers should take the role of teaching and raising them accordingly. The role of the father is to ensure that they get educated by paying their school fees and other things required like for example buying clothes and paying rent so that you ensure they live well.(Fathers of adolescent boys and girls)

Often being away from home for most of the day, fathers did not have time to spend with adolescents, a narrative that was common from discussions with both mothers and fathers.

They don't have time for children because they go to work very early in the morning and they come in the evening and maybe they get children are asleep and it is hard to wake them up.(Mothers of adolescent boys)

The challenge is that we are busy throughout the day and we come back home late that is why you may get them spending more time with their mothers. (Fathers of adolescent boys)

Even though they were often absent, fathers gave their expectations on how the children should be brought up portraying the entrenched gender power dynamics where men have more power and control over women even in a family setting.

Mothers may want to raise their children (in the) same way they were raised because they think they were raised in a good way but the role of the father is to ensure that they are raised according to the way he wants not the way his wife wants.(Fathers of adolescent boys and girls)

\section{Discussion}


The study aimed to explore gendered parenting of early adolescents in Viwandani, an informal settlement in Nairobi. We found differences in parenting approaches used by mothers and fathers as well as differences on how boys and girls were parented. Similar to findings from previous studies, fathers held more to traditional gender role attitudes as compared to mothers $(17,19)$. Fathers had different expectations for their adolescent girls and boys in respect to their roles and responsibilities presently and in the future. They perceived girls as responsible for most household chores such as cooking and cleaning and boys only engaged in household chores as a way of 'offering help to their sisters'. Fathers also expressed their expectations for their daughters to get married and be good wives while they were silent on their expectations for their sons to be good husbands. On the other hand, mothers had similar expectations for their daughters and sons and assigned them similar roles and responsibilities, implying that mothers may challenge the traditional gender norms that exist in different societies.

There were also gender differences in SRH communication and freedom of movement for adolescent boys and girls. This was largely attributed to perceptions that girls were more at risk of poor SRH outcomes than boys, and thus in need of information and protection (27). Consistent with previous studies $(6,28), \mathrm{SRH}$ communication commonly targeted girls and was generally centered on averting pregnancy through sex avoidance. Similar to a study examining the gender socialization process among boys and girls aged 11-13 years in China (29), we found that boys enjoyed more freedom of movement and interaction with peers compared to girls. Another study using data from the Global Early Adolescent Study (GEAS) also found that girls' movement was more restricted than boys and attributed girls' restriction to greater SRH risks and vulnerabilities (27). The lack of freedom of movement on one hand limits girls' ability to create social networks and peer interactions necessary for building social capital (30). On the other hand, it gives boys more time to engage in unsupervised activities outside the home. Such activities are likely to expose young boys to other risks such as interpersonal violence, crime and substance use which are common in urban informal settlements $(27,31)$.

We also found that fathers and mothers took up different roles in the family setting. Fathers' role was perceived to be that of provision and protection while that of mothers to be nurturance and guidance. This is consistent with the traditional expectation that the woman's role is that of taking care of the home and children while men's role is to provide for the family $(13,32)$. In a setting where the reported levels of unemployment for both men and women are high, it implies that women maybe as busy as men looking for a living in addition to investing more hours in parenting (26).

According to the Socio-Cognitive Theory, children learn gender stereotypes from observing the differential performances of male and female in their environment, including at the household level (15). They are more likely to adopt behaviours of people they identify with within their environment (15). Therefore, boys are most likely to adopt their fathers' behaviours and girls their mothers' as they start identifying with socio-cultural roles and expectations associated with each gender (4). In the process, inherent harmful stereotypical norms about masculinity and femininity which perpetuate gender inequalities are passed to adolescents. Mothers holding more equitable gender role attitudes was a positive finding in this study, 
given that mothers have been found to be the primary socialization agents as they tend to spend more time with the children than fathers $(4,29)$

Our study findings should be interpreted with the following limitations in mind. First, we are cognisant that due to social desirability, the participants could present views that they thought were 'right' and or desirable to the interviewer. Secondly, the FGDs did not take into account the different family arrangements such as single parenthood and household with children of the same gender during data collection. We do recognise that this can have an effect on the views on parenting where one parent plays the combined roles of the mother and the father or in instances where the assignment of roles and responsibilities is affected in a household with children of the same gender.

\section{Conclusion}

The results of this study imply that gendered parenting exists along with male and female roles differing considerably within households. The disconnect in gender beliefs between men and women implies a greater need to engage men in gender equitable programming given they have been found to hold more gender inequitable attitudes. Deconstructing harmful stereotypical norms held by parents requires addressing beliefs and attitudes at the community level since parents are likely to be responding to sociocultural norms and expectations.

\section{Abbreviations}

APHRC: African Population and Health Research Center

GEAS: Global Early Adolescent Study

FGD: Focus group discussions

NUDHSS: Nairobi Urban Health and Demographic Surveillance System

SRH: Sexual and reproductive health

\section{Declarations}

\section{Availability of data and materials}

The data analysed for the current study are available from the authors upon request and with permission from the African Population and Health Research Center and the study's Principal Investigator.

\section{Acknowledgements}

We are grateful to Joan Njagi who was the qualitative lead in the study and led the data collection, Kevin Owuor and Robert Mbeki who assisted with data collection and lastly to the study participants. 


\section{Funding}

The study was funded by International Development Research Centre (IDRC) (Grant number 108676-002). The statements made and views expressed are solely the responsibility of the authors.

\section{Contributions}

VN conceptualised the manuscript, conducted the analysis, and wrote the first draft of the manuscript. $\mathrm{BM}, \mathrm{MM}$ and $\mathrm{MB}$ reviewed and contributed towards the manuscript. All authors critically reviewed and approved the final manuscript.

\section{Ethics declaration}

\section{Ethics approval and consent to participate}

The protocol including tools/interview guides were reviewed and approved by AMREF Health Africa's Ethics and Scientific Review Committee (Ref AMREF-ESRC P564/2018). The National Commission for Science, Technology and Innovation in Kenya gave the permit (Ref: NACOSTI/P/19/16027/27880) to conduct the study. Additional approvals from county administration were obtained and written informed consent obtained from the parents/guardians before the commencement of the interview.

\section{Consent for publication}

Not applicable

\section{Competing interests}

The authors declare that they have no competing interests.

\section{References}

1. McCarthy K, Brady M, Hallman K. Investing when it counts: Reviewing the evidence and charting a course of research and action for very young adolescents. New York; 2016.

2. Sawyer SM, Afifi RA, Bearinger LH, Blakemore SJ, Dick B, Ezeh AC, et al. Adolescence: A foundation for future health. Lancet. 2012;379(9826):1630-40.

3. Choudhury S, Blakemore SJ, Charman T. Social cognitive development during adolescence. Soc Cogn Affect Neurosci [Internet]. 2006 Dec 1 [cited 2020 Nov 2];1(3):165-74. Available from: https://academic.oup.com/scan/article/1/3/165/2362733

4. Kågesten A, Gibbs S, Blum RW, Moreau C, Chandra-Mouli V, Herbert A, et al. Understanding factors that shape gender attitudes in early adolescence globally: A mixed-methods systematic review. PLoS One. 2016;11(6):1-36.

5. Bello BM, Fatusi AO, Adepoju OE, Maina BW, Kabiru CW, Sommer M, et al. Adolescent and parental reactions to puberty in Nigeria and Kenya: A cross-cultural and intergenerational comparison. $J$ 
Adolesc Heal. 2017 Oct 1;61(4):S35-41.

6. Wamoyi J, Fenwick A, Urassa M, Zaba B, Stones W. Parent-child communication about sexual and reproductive health in rural Tanzania: Implications for young people's sexual health interventions. Reprod Health. 2010;7(1):1-18.

7. Wilson EK, Koo HP. Mothers, fathers, sons, and daughters: Gender differences in factors associated with parent-child communication about sexual topics. Reprod Health. 2010;7(1).

8. Mbachu CO, Agu IC, Eze I, Agu C, Ezenwaka U, Ezumah N, et al. Exploring issues in caregivers and parent communication of sexual and reproductive health matters with adolescents in Ebonyi state, Nigeria. BMC Public Health. 2020;20(1):1-10.

9. Endendijk JJ, Groeneveld MG, Bakermans-kranenburg MJ, Mesman J. Gender-differentiated parenting revisited: Meta-analysis reveals very few differences in parental control of boys and girls. PLoS One. 2016;11(7):3-33.

10. Biswas S, Sharma P. To study the gender-wise difference in parenting styles of mother and father. Sch J Psychol Behav Sci. 2019;2(5):236-48.

11. Vyas K, Islamia JM, Bano S, Islamia JM. Child 's gender and parenting styles. 2018;(November).

12. Carlo G, Mcginley M, Hayes R, Batenhorst C, Wilkinson J. Parenting styles or practices? Parenting , sympathy , and prosocial behaviors among adolescents. J Genet Psychol. 2007;168(2)(November 2013):147-176.

13. Halpern HP, Perry-Jenkins M. Parents' gender ideology and gendered behavior as predictors of children's gender-role attitudes: A longitudinal exploration. Sex Roles. 2017;74(11).

14. MacPherson EE, Richards E, Namakhoma I, Theobald S. Gender equity and sexual and reproductive health in Eastern and Southern Africa: A critical overview of the literature. Glob Health Action. 2015;8(1).

15. Bussey K, Bandura A. Social cognitive theory of gender development and differentiation. Am Psychol Assoc. 1999;

16. Martin CL, Ruble DN, Szkrybalo J. Cognitive theories of early gender development. Psychol Bull. 2002;128(6):903-33.

17. Lytton H, Romney DM. Parents' differential socialization of boys and girls: A Meta-analysis. Psychol Bull. 1991;109(2):267-96.

18. Mesman J, Groeneveld MG. Gendered parenting in early childhood: Subtle but unmistakable if you know where to look. Child Dev Perspect. 2018;12(1):22-7.

19. Marks JL, Lam CB, McHale SM. Family patterns of gender role attitudes. Sex Roles. 2009;61(34):221-34.

20. Petkovic S, Milic T. Parenting adolescents. Vol. 15, UNICEF. 2018.

21. Beguy, D; Mumah, J; Wawire, S; Muindi, K; Gottschalk, L; Kabiru C. Status report on the sexual and reproductive health of adolescents living in urban slums in Kenya. STEP UP Technical Working Paper. 2013;(September). 
22. Muiya BM. The Nature, challenges and consequences of urban youth unemployment: A case of Nairobi City, Kenya. Univers J Educ Res [Internet]. 2014 [cited 2020 Jul 23];2(7):495-503. Available from: http://www.hrpub.org

23. Beguy D, Elung'ata P, Mberu B, Oduor C, Wamukoya M, Nganyi B, et al. Health \& Demographic Surveillance System Profile: The Nairobi Urban Health and Demographic Surveillance System (NUHDSS). Int J Epidemiol [Internet]. 2015 [cited 2020 Mar 5];462-71. Available from: https://academic.oup.com/ije/article-abstract/44/2/462/752904

24. Beguy D, Mumah J, Gottschalk L. Unintended pregnancies among young women living in urban slums: Evidence from a prospective study in Nairobi City, Kenya. PLoS One. 2014;9(7).

25. Kabiru CW, Beguy D, Undie CC, Zulu EM, Ezeh AC. Transition into first sex among adolescents in slum and non-slum communities in Nairobi, Kenya. J Youth Stud. 2010;

26. African Population and Health Research Center (APHRC). Population and health dynamics in Nairobi's informal settlements: Report of the Nairobi Cross-sectional Slums Survey (NCSS) 2012. 2014.

27. Mmari K, Moreau C, Gibbs SE, De Meyer S, Michielsen K, Kabiru CW, et al. 'Yeah, I've grown; I can't go out anymore': differences in perceived risks between girls and boys entering adolescence. Cult Heal Sex [Internet]. 2018;20(7):787-98. Available from: http://doi.org/10.1080/13691058.2017.1382718

28. Muhwezi WW, Katahoire AR, Banura C, Mugooda H, Kwesiga D, Bastien S, et al. Perceptions and experiences of adolescents, parents and school administrators regarding adolescent-parent communication on sexual and reproductive health issues in urban and rural Uganda Adolescent Health. Reprod Health [Internet]. 2015;12(1):1-16. Available from: http://dx.doi.org/10.1186/s12978015-0099-3

29. Basu S, Zuo X, Lou C, Acharya R, Lundgren R. Learning to be gendered: Gender socialization in early adolescence among urban poor in Delhi, India, and Shanghai, China. J Adolesc Heal [Internet]. 2017;61(4):S24-9. Available from: http://dx.doi.org/10.1016/j.jadohealth.2017.03.012

30. Morgan A, Haglund BJA. Social capital does matter for adolescent health: Evidence from the English HBSC study. Health Promot Int. 2009;24(4):363-72.

31. Ombati M, Ombati VFO. Resilience of children and youth negotiating urban vulnerabilities and livelihoods in the Langas slums of Eldoret, Kenya. Urbana [Internet]. 2016 [cited 2020 Oct 7];17:1-13. Available from: http://www.urbanauapp.org/

32. Moon M, Hoffman CD. Mothers' and fathers' differential expectancies and behaviors: Parent $\times$ child gender effects. J Genet Psychol. 2008;169(3):261-80.

\section{Supplementary Files}

This is a list of supplementary files associated with this preprint. Click to download.

- Nyakangietal.2021.SRQRchecklist.docx 